\title{
O IMAGINÁRIO SOCIAL COMO UM FATOR PARA CASOS DE EVASÃO E NÃO PREEN- CHIMENTO DE VAGAS NA UNIPAMPA - CAMPUS SÃO BORJA
}

GABRIEL SAUSEN FEIL UNIVERSIDADE FEDERAL DO PAMPA SÃO BORJA, RIO GRANDE DO SUL, BRASIL GABRIEL.SAUSEN.FEIL@GMAIL.COM

MARCIA ESCOBAR TERRA UNIVERSIDADE FEDERAL DO PAMPA SÃO BORJA, RIO GRANDE DO SUL, BRASIL MARCIATERRAX@GMAIL.COM

JÚLIA ROCHA PAZ UNIVERSIDADE FEDERAL DO PAMPA SÃO BORJA, RIO GRANDE DO SUL, BRASIL RP_JULIA@HOTMAIL.COM 


\section{O IMAGINÁRIO SOCIAL COMO UM FATOR PARA CASOS DE EVASÃO E NÃO PREENCHIMENTO DE VAGAS NA UNIPAMPA - CAMPUS SÃO BORJA}

Resumo: Este trabalho tem como objetivo levantar a hipótese de que um dos fatores determinantes para a evasão e não preenchimento de vagas na UNIPAMPA - Campus São Borja está relacionado com o imaginário social que se tem de vida universitária. Reflete, então, sobre possibilidades de ações publicitárias que podem contribuir para a melhora gradativa desse imaginário. Utiliza dois autores para a reflexão: Cornelius Castoriadis, por meio de A Instituição Imaginária da Sociedade (1975), e Juremir Machado da Silva, por meio de As Tecnologias do Imaginário (2012). O trabalho percebe que os estudantes e/ou futuros estudantes podem levar como fator impulsionador de evasão ou não preenchimento das vagas essa não sincronia entre a cidade e o imaginário.

Palavras-chave: Evasão universitária. Imaginário social. Publicidade.

\section{EL IMAGINARIO SOCIAL COMO FACTOR EN LOS CASOS DE DESER- CIÓN Y FALTA DE VACANTES EN UNIPAMPA - CAMPUS SÃO BORJA}

Resumen: Este trabajo tiene como objetivo levantar la hipótesis de que uno de los factores determinantes para la evasión y la no ocupación de vacantes en UNIPAMPA - Campus São Borja esté relacionado con el imaginario social de la vida universitaria. Reflexiona, luego, sobre las posibilidades de acciones publicitarias que pueden contribuir a la mejora paulatina de este imaginario. Utiliza dos autores para la reflexión: Cornelius Castoriadis, mediante de La Institución Imaginaria de la Sociedad (1975), y Juremir Machado da Silva, mediante de As Tecnologias do Imaginário (2012). El trabajo nota que los estudiantes y/o futuros estudiantes pueden tomar como factor impulsor de la evasión o no cubrir las vacantes esta falta de sincronía entre la ciudad y lo imaginario.

Palabras clave: Evasión universitaria. Imaginario social. Publicidad.

\section{THE SOCIAL IMAGINARY AS A FACTOR TO CASES OF EVASION AND} NOT FULFILLING OF THE VACANCIES IN UNIPAMPA - CAMPUS SÃO BORJA

Abstract: This paper aims to raise the hypothesis that one of the determinant factors for the evasion and non-full filling of vacancies at UNIPAMPA São Borja Campus is related to the social imaginary of university life. Then, reflect on the possibilities of advertisement actions that could gradually improve this imaginary. It uses two authors for the reflection: Cornelius Castoriadis, through The Imaginary Institution of Society (1975), and Jure- 
mir Machado da Silva, through As Tecnologias do Imaginário (2012). The work realizes that students and/or future students can take this lack of synchrony between the city and the imaginary as a driving factor for evasion or non-filling of vacancies.

Keywords: University evasion. Social Imaginary. Advertisement.

\section{INTRODUÇÃO}

Nossa intenção com este trabalho é, primeiro, levantar a hipótese de que um dos fatores determinantes para a evasão e para o não preenchimento de vagas no Campus São Borja da Universidade Federal do Pampa (UNIPAMPA) está relacionado com o imaginário social que as pessoas conservam em relação à cidade em questão, que não apresenta características de vida universitária. Em segundo lugar, refletir sobre possibilidades de ações publicitárias poderem trazer alguma contribuição para a mudança gradativa desse imaginário.

Para chegarmos a esses objetivos, seguimos o seguinte percurso: apresentamos as características que compõem a UNIPAMPA - Campus São Borja, a fim de esclarecermos o cenário de evasão e não preenchimento das vagas; abordamos o conceito de imaginário social, que, de acordo com Silva (2012, p. 12), "diferente do imaginado - projeção irreal que poderá se tornar real o imaginário emana do real, estrutura-se como ideal e retorna ao real como elemento propulsor"; levantamos os elementos constitutivos da cidade de São Borja. Logo, apresentamos o conceito de publicidade, para entendermos como tal atividade se encaixa neste trabalho, de modo que possamos mostrar as formas existentes de ações publicitárias; por fim, apontamos maneiras pelas quais a publicidade pode contribuir no cenário da cidade de São Borja para uma mudança gradativa do imaginário social em questão.

Em nível introdutório, torna-se importante fazermos algumas ressalvas: (a) esse trabalho visa refletir sobre uma das possíveis causas da evasão e do não preenchimento das vagas na UNIPAMPA - campus São Borja, pois esses fenômenos não podem ser reduzidos a uma única causa; (b) não estamos equiparando os imaginários; em verdade, nunca se trata de um mesmo imaginário, afinal, este é sempre uma construção singular; (c) o segundo objetivo não é sobre o efeito que a publicidade causará, mas sobre uma reflexão que busca indicar possibilidades dela agir frente ao imaginário; (d) ações publicitárias não são capazes de resolverem a questão (se trata apenas de uma contribuição parcial). Além disso, (e) as possibilidades publicitárias a 
serem apontadas não buscam enfrentar todos os tipos de evasão e não preenchimento das vagas na UNIPAMPA - campus São Borja; buscam, apenas, enfrentar os casos em que o estudante evadiu ou não aproveitou uma vaga em função do que ele imagina da cidade.

Podemos resumir o caso que nos interessa da seguinte forma: aquele em que o estudante ou potencial estudante enfrenta uma projeção imaginária cumprida pela metade, que é quando o indivíduo projeta uma situação e ela se concretiza, mas não completamente, apenas parte dela. A metade cumprida diz respeito ao fato do estudante ou do potencial estudante concretizar a ideia, nutrida durante sua trajetória de vida, de ser um universitário, de levar uma vida universitária; já a metade não cumprida tange o fato do estudante ou potencial estudante acabar não levando a tal vida universitária em uma cidade já historicamente relacionada com a fama de vida universitária.

\section{IMAGINÁRIO SOCIAL}

Neste capítulo apresentamos o conceito de imaginário social. Utilizamos dois autores para nossa reflexão: Cornelius Castoriadis, por meio de A Instituição Imaginária da Sociedade (1975), e Juremir Machado da Silva, sobretudo, por meio de As Tecnologias do Imaginário (2012).

\subsection{A concepção do conceito de imaginário por Cornelius Castoriadis}

O conceito de imaginário social tem como origem os estudos do filósofo e psicanalista Cornelius Castoriadis (1975). O autor afirma (p. 154) que, quando falamos de imaginário, estamos nos referindo a algo já inventado, com aspecto de invenção absoluta, uma história criada em todas as suas partes. Nessa história, ocorre um deslizamento ou deslocamento de um sentido racional, envolvendo fantasias criadas na mente humana com o auxílio da emoção. Isto é, o imaginário implica uma realidade pré-racional, alterada por aspectos irracionais que variam em cada cultura.

Para Castoriadis (1975), todas as sociedades são responsáveis por construir seus respectivos imaginários. Esses imaginários correspondem a leis, crenças, instituições, comportamentos, tradições, estilos de vida. Com isso, ele adota a existência de uma "instituição imaginária da sociedade", na qual foca nesses três argumentos: instituição, imaginário e sociedade para compreender sua linha de pensamento. Podemos dizer que o imaginário e as instituições se tornam sociais, já que se constituem por aspectos gerais e 
que são repetitivos em todas as sociedades. É no coletivo que o imaginário se manifesta, apesar de surgir no individual (CASTORIADIS, 1975).

Ademais, ligado à semiótica, o imaginário necessita do simbólico para se constituir, não apenas para se exprimir, mas também para "existir", ou seja, para passar do virtual a qualquer coisa a mais (CASTORIADIS, 1975). Qualquer tipo de construção que o indivíduo possui no seu imaginário, pode ser fantasia, delírio, sonhos, são feitos através de “imagens"; e essas imagens, no inconsciente do ser humano, se apresentam de uma maneira, com o auxílio da subjetividade de cada um. Essa construção feita através de imagens, variando para cada pessoa, é o que Castoriadis (1975) intitula de "função simbólica".

O simbolismo também pressupõe a capacidade do imaginário, pois faz com que o indivíduo enxergue determinada situação ou objeto de forma diferente do sentido original. Na medida em que o imaginário vai se elencando no pensamento, ele vai adquirindo níveis, podendo chegar até na rotulação de imaginário radical. Castoriadis (1975) comenta que, logo após a formulação do imaginário nos indivíduos, ele se torna uma representação. O imaginário possui como características laços históricos cultivados em cada cultura e grupos sociais - quando o imaginário atinge o nível radical, ele pode se tornar uma representação. Ou seja, a representação remete a algo do presente e o imaginário é responsável pela construção do presente com auxílio de lembranças do passado.

Por se tratar de produção coletiva, os indivíduos identificam as diferentes percepções que os demais têm de si. Em outras palavras: "como eles [os indivíduos] enxergam-se sendo parte de um grupo social e através disso esboçam as suas identidades e objetivos, detectam seus inimigos e, ainda, organizam seu passado, presente e futuro" (BACZKO, 1986, p. 16 apud ESPIG, 2004, p. 51). Além disso, essas identidades e objetivos estabelecidos nem sempre são questionados, tornando-se um pensamento inserido no inconsciente de cada indivíduo na sua cultura. Assim, é como se não existisse a opção de se desviar dessa tradição de pensamento.

\subsection{A concepção do conceito de imaginário por Juremir Machado da} Silva

A definição de imaginário, segundo Silva (2012), ganha força na última década do século XX. Silva (2012) revisa o conceito a partir de teóricos como 
Gilbert Durand, Michel Maffesoli, Cornelius Castoriadis e Jacques Lacan, ressaltando que, para Durand e Maffesoli, a abordagem do imaginário não se tratava de uma novidade, pois esse conceito já tinha sustento próprio.

Silva (2012) resgata que Lacan ordena seu pensamento através do uso da filosofia e psicanálise, definindo o imaginário como um reservatório de imagens que antecedem uma cultura. $O$ real se torna um excesso que não pode ser simbolizado (no sentido de que, por conta de sua singularidade, vê-se impossibilitado de ser expresso por meio de símbolos já estabelecidos) e, para isso, necessita do imaginário, pois ele retrata as ilusões de cada indivíduo.

De acordo com Silva (2012), na visão de Maffesoli, o imaginário se trata de uma força, energia que, ao mesmo tempo, é um patrimônio de um grupo, uma fonte comum de sensações, lembranças, afetos e estilos de vida. Podemos perceber que, diante das diversas interpretações do conceito de imaginário, todas nos mostram que ele se trata de uma abordagem pré-racional.

O imaginário pode ser considerado um depósito que conta com imagens, sentimentos, lembranças, experiências, idealizações, etc., que, através do auxílio de grupos sociais, organiza estilos de vida, modos de ser, de agir, de sentir. Silva (2012, p. 13) explica que a construção do imaginário em cada indivíduo se dá por "identificação (reconhecimento de si no outro), apropriação (desejo de ter o outro em si) e distorção (reelaboração do outro para si)". Ele se sustenta através da aceitação do modelo do outro; disseminação dentro da lógica de igualdade na diferença e imitação no qual se diferencia de um todo por propagação de apenas uma parte (SILVA, 2012, p. 13). Esse conceito apresenta "o 'eu' (parte) no 'outro' (todo). Mostra como se permanece individual no grupo e grupal na cultura” (p. 14). Percebemos que, mesmo com a existência de grupos sociais nas culturas, cada indivíduo se adequa a esse imaginário social.

Silva (2012) utiliza a concepção de Maffesoli para ressaltar que o imaginário vai além da cultura, pois é um estado de espírito, transfigurador, que caracteriza a "errância" de um povo; com isso, nos deixa em constante movimento. $O$ imaginário social se instala por contágio através das relações sociais as quais são compartilhadas entre os indivíduos. É uma espécie de fator racional e irracional que impulsiona a ação humana (SILVA, 2012).

Percebemos que o campo do imaginário é interdisciplinar e complexo em sua abordagem, pois existe uma multiplicidade de teorias apresentadas 
para explicá-lo (SERBENA, 2003). De qualquer maneira, destacamos aqui os elementos constitutivos do conceito de imaginário que são relevantes para nossa discussão acerca da defesa do pressuposto que apresentamos de início: o imaginário é algo inventado, ou seja, construído; o imaginário lida com o inconsciente, o intangível; por vezes, o imaginário desloca o sentido racional; relações sociais fortalecem o imaginário; o imaginário pode ser mudado (importância do auxílio da publicidade); o imaginário é uma herança; o indivíduo organiza sua vida com base no imaginário; o imaginário não é problematizado; o imaginário tende a ser conservador, a não mudar; é através do imaginário que o indivíduo constrói condutas e estilos de vida.

\section{A UNIPAMPA - CAMPUS SÃO BORJA}

A Universidade Federal do Pampa (UNIPAMPA) surgiu a partir do contexto de reivindicação da comunidade regional, que encontrou apoio através da criação da política de expansão e renovação das instituições públicas de ensino superior instituída na década de 2000. No Rio Grande do Sul, tal ampliação ocorreu mediante Acordo de Cooperação Técnica entre o Ministério da Educação (MEC), a Universidade Federal de Pelotas (UFPel) e a Universidade Federal de Santa Maria (UFSM). As duas últimas dividiram entre si a implantação dos campi, localizados nas seguintes cidades: Alegrete, Bagé, Caçapava do Sul, Dom Pedrito, Itaqui, Jaguarão, Santana do Livramento, São Borja, São Gabriel e Uruguaiana. Dessa forma, se trata de uma instituição de ensino superior multicampi. Sua implementação foi anunciada em 27 de julho de 2005, pelo então presidente Luiz Inácio Lula da Silva em ato público no município de Bagé. A UNIPAMPA foi criada pela Lei 11.640 de 11 de janeiro de 2008, intitulada como "Fundação Universidade Federal do Pampa" (UNIPAMPA, 2009).

Atualmente, a UNIPAMPA - campus São Borja conta com cursos da área de Ciências Sociais e Ciências Humanas: Jornalismo, Publicidade e Propaganda, Relações Públicas, Serviço Social, Ciência Política e Ciências Humanas (Licenciatura) (UNIPAMPA, 2017).

O processo seletivo de ingresso ocorre por meio do Sistema de Seleção Unificada (SiSU), gerenciado pelo MEC. Nele, as instituições de ensino superior públicas disponibilizam vagas para os participantes do Exame Nacional do Ensino Médio (ENEM), que ocorre anualmente. Cada curso do campus São Borja oferece 50 vagas para os novos discentes que são segmentadas pela política de cotas e efetivadas através da Primeira Chamada, Segunda 
Chamada e Lista de Espera pela Nota do ENEM (UNIPAMPA, 2017).

A UNIPAMPA - campus São Borja possui uma estrutura qualificada, corpo docente integrado por mestres, doutores e pós-doutores; os seis cursos que a universidade apresenta possuem classificação favorável em termos de avaliação. Em termos de estrutura física, ela conta com laboratórios de rádio, fotografia, TV, agências experimentais e, desde 2014, possui o Restaurante Universitário (RU) como recurso disponível aos estudantes.

No quesito de avaliação dos cursos, em 2017 o curso de Ciências Humanas e Ciência Política receberam nota máxima pelo MEC (média 5), considerado como excelente em sua escala. Nessa avaliação, levou-se em conta três aspectos: Corpo Docente, Tutorial e Infraestrutura, Organização Didático-Pedagógica, além das subdivisões de cada um desses itens. $O$ curso de Serviço Social, na última avaliação, ficou com a média 4. Publicidade e Propaganda, Jornalismo e Relações Públicas possuem nota 4 segundo o MEC (UNIPAMPA, 2016).

Além desses aspectos apresentados, a universidade conta com diversos recursos pedagógicos disponibilizados aos acadêmicos, como o Programa Bolsa Permanência (PBP), que disponibiliza ao estudante os programas de auxílio moradia, alimentação, transporte, instalação estudantil e auxílio creche. Conforme os dados atuais da secretaria acadêmica, dos 882 alunos matriculados na UNIPAMPA - campus São Borja, 164 alunos recebem o auxílio do Programa (UNIPAMPA, 2016). Além do PBP, os campi da UNIPAMPA contam com os projetos de pesquisa e extensão, que, quando inseridos, alguns alunos são contemplados com bolsas.

Ainda assim, a UNIPAMPA - campus São Borja apresenta um cenário significativo de evasão e não preenchimento de vagas pelos cursos disponibilizados. Dessa forma, ressaltamos os pontos que constituem essa universidade, a fim de contribuir para nossa reflexão: estrutura qualificada; corpo docente qualificado; classificação favorável em termos de avaliação; presença de RU; Programa Bolsa Permanência (PBP); projetos de extensão; projetos de pesquisa.

São esses pontos que instigam a nossa reflexão. Dessa forma, cogitamos que alguns casos de evasão e não preenchimento acontecem não pela universidade em si, mas pelo imaginário social construído sobre estudar em uma cidade que não apresenta características de vida universitária.

Vale ressaltar os dados de evasão e não preenchimento de vagas disponibilizado pela UNIPAMPA - campus São Borja. Sendo assim, apresentamos 
o seguinte cenário: em relação à evasão dos estudantes da UNIPAMPA campus São Borja, contamos com dados do ano de 2016, disponibilizados pelo Núcleo de Desenvolvimento Educacional (NuDE): o curso de Ciências Humanas teve 51 alunos evadidos; Ciência Política teve 40; Jornalismo, 26; Publicidade e Propaganda, 24; Serviço Social, 29; Relações Públicas, 43 alunos evadidos.

No histórico de não preenchimento de vagas, contamos com dados do ano de 2017 disponibilizados na secretaria acadêmica da universidade. Das 300 vagas oferecidas nos seis cursos de graduação, foram preenchidas 254 . Na divisão das vagas por cursos, em Ciências Humanas, o total de ingressantes em 2017 foi de 50, preenchendo todas as vagas. Em Ciência Política, 42. Jornalismo e Publicidade e Propaganda, 33 matriculados em cada. Relações Públicas, 50. Serviço Social, 46 novas matrículas.

Notamos, de acordo com os índices de evasão e não preenchimento de vagas, que Ciências Humanas e Relações Públicas, apesar de serem os cursos que tendem a preencher todas as vagas, também se tornam os que possuem mais alunos evadidos. Logo, temos Ciência Política com mais matrículas realizadas, juntamente com Serviço Social, e também no quesito evasão de vagas. Os cursos de Publicidade e Propaganda e Jornalismo são os que menos preenchem as vagas disponibilizadas e, como consequência, seus números de evasão são menores.

Percebemos que o fato de a UNIPAMPA - campus São Borja ser uma instituição pública de ensino superior de qualidade não é suficiente para que os estudantes ou possíveis ingressantes deixem de evadir ou não preencham as vagas ofertadas.

\section{A CIDADE DE SÃO BORJA}

São Borja está localizada na fronteira oeste do estado do Rio Grande do Sul, é banhada pelo Rio Uruguai e possui fronteira com o município de Santo Tomé, da província de Corrientes, Argentina. Ela foi a primeira cidade dos Sete Povos das Missões, fundada em 1682 por um grupo de padres jesuítas. Seu nome faz referência ao terceiro general dos jesuítas, "São Francisco de Borja", que contribuiu para seu estabelecimento. Atualmente, o município possui 62.897 habitantes (PREFEITURA DE SÃO BORJA, 2010).

Em termos históricos, é a cidade mais antiga do estado gaúcho, está entre as mais antigas do Brasil e o município foi consagrado, através do Artigo 82, inciso V da Constituição do Estado do Rio Grande do Sul, como a "Terra 
dos Presidentes", por ser a cidade natal de dois ex-presidentes brasileiros: Getúlio Vargas e João Goulart (PREFEITURA DE SÃO BORJA, 2010).

Mencionamos os seguintes bairros do município de São Borja, de acordo com informações disponibilizadas no site da Prefeitura de São Borja, a fim de mostrar o que cada um possui como característica que possa contribuir para o intuito deste trabalho:

Centro: Apresenta a principal concentração populacional e presença significativa de moradia dos universitários. Outro fator a ser apontado são os seguintes pontos turísticos: Museu Casa de Getúlio Vargas, Memorial Casa de João Goulart e Museu Apparício Silva Rillo (PORTAL DO BRASIL, 1999); Passo: Esse bairro conta com a presença de diversas classes, mas se destaca pelas moradias populares. Nele está o Campus da UNIPAMPA e o Cais do Porto, que é onde o Rio Uruguai está localizado (PORTAL DO BRASIL, 1999); Bettim: É o local onde está inserido o Instituto Federal Farroupilha - campus São Borja. Apresenta índices de um bairro de classe média, sendo um dos mais tranquilos do município em termos de segurança (PORTAL DO BRASIL, 1999); Tiro: Nesse bairro está inserido o Parque de Exposições, o Sindicato Rural, a Sede Campestre do Clube Comercial, a Sede de Moradores da Vila Cabeleira e a antiga Universidade da Região da Campanha (URCAMP). No Parque de Exposições, acontece anualmente a Fenaoeste, evento que agrega desenvolvimento econômico a São Borja (RÁDIO CULTURA, 2009) e atrai públicos das regiões mais próximas (PORTAL DO BRASIL, 1999); José Pereira Alvarez: É onde fica a antiga Estação Ferroviária, onde foram construídos o Centro Cultural de São Borja e o Mercado Público Municipal; além disso, no bairro há quartéis, o aeroporto João Manoel e o Jóquei Club (PORTAL DO BRASIL, 1999); Maria do Carmo: Bairro sede da Associação dos Funcionários Públicos Municipais (AFPM); conta com aspectos mais naturais, contendo áreas de campos de futebol, vôlei, basquete e o Museu Ergológico de Estância - Os Angueras (PORTAL DO BRASIL, 1999);

Florêncio Guimarães: Aqui se localiza o Estádio Vicent Goulart e a Associação Esportiva São Borja (PORTAL DO BRASIL, 1999).

São Borja conta, também, com as seguintes instituições de ensino: Universidade Federal do Pampa; Instituto Federal Farroupilha; Universidade Estadual do Rio Grande do Sul; UNIDERP - Universidade Anhanguera e UNINTER - Grupo Educacional Uninter (FOLHA DE SÃO BORJA, 2017). Além dessas informações formais, há alguns aspectos sobre a cidade de São Borja que, uma vez salientados, contribuem para a nossa discussão: 
Aeroporto pequeno: A cidade conta com o Aeroporto João Manoel, que possui uma pista de 1500 metros de asfalto e condições para receber aviões de médio porte. Em 2015 foi lançado o edital para a sua reforma. Após o término dessa reforma, o aeroporto suportará aeronaves de até 72 passageiros (FOLHA DE SÃO BORJA, 2017). Entretanto, até o presente momento, o aeroporto não possibilita voos comerciais, que são os que poderiam interessar ao público universitário.

Não há cinema: Entre 1915 e 2009 houve sete tentativas de estabilizar a prática do cinema na cidade, mas não se viabilizaram ao longo do tempo (SARMANHO, 2009).

Transporte público problemático: Em termos de locomoção, o município conta com uma empresa de mobilidade urbana que utiliza o ônibus como transporte. Porém, os horários disponibilizados por ela são limitados. Os horários que levam à UNIPAMPA sofrem atrasos e, por vezes, não passam no horário previsto, fazendo com que os estudantes que dependem do transporte para chegar na universidade passem por surpresas inesperadas.

Poucas opções de lazer: Poucas atrações na cidade que chamem a atenção do público estudante. Os diversos museus e características históricas muitas vezes não chamam a atenção dos universitários.

Distante de grandes centros: São Borja está localizada na região mais pobre do estado e distante dos grandes centros. Destacamos as distâncias de 294 km entre São Borja e Santa Maria (considerada cidade universitária) e 584 km entre São Borja e a capital do estado, Porto Alegre (IBGE, 2016).

Ausência de shoppings: No senso comum, a existência de shopping costuma ser critério para a formação da ideia de entretenimento tradicional para o público universitário. Assim, a não presença desse tipo de estabelecimento costuma funcionar como um descrédito.

Cidade agrícola: A economia da cidade se baseia no setor primário, especificamente da produção do arroz (FOLHA DE SÃO BORJA, 2017). Contudo, a estética agrícola/rural tende a se conflitar com a estética universitária/urbana, sobretudo, quando o que está em questão são áreas humanas e sociais.

Poucas vagas de estágios: Por se tratar de uma cidade agrícola, São Borja acaba por contar com poucas empresas dos ramos ligados aos cursos oferecidos pela UNIPAMPA - campus São Borja, gerando poucas alternativas de estágios para quem pretende se inserir no mercado durante a graduação.

Vida noturna limitada: Em geral, quando falamos em vida noturna, fazemos relações com casas noturnas tradicionais/badaladas. Nesse sentido, 
apesar de a cidade apresentar opções para a vida noturna, ela se limita a oferecer pequenos bares ou pizzarias e restaurantes.

Apesar desses possíveis fatores da cidade que podem contribuir para um imaginário negativo sobre São Borja, ressaltamos alguns aspectos da cidade que muitas vezes passam despercebidos ou que podem, até mesmo, serem mais valorizados quando adequados a um melhor contexto de apresentação ao público universitário:

Cidade histórica: São Borja conta com diversos aspectos que a deixam como uma cidade na qual sua história é conservada. Por ser a cidade natal de dois ex-presidentes do Brasil (Getúlio Vargas e João Goulart), possui, em seu território, diversas memórias referentes a essa característica. Também podemos citar a presença de características jesuítas, pois se trata de um local que foi fundado por padres jesuítas.

Eventos e lazer no Centro Esportivo Cel. Vargas (Parcão): O Parcão é conhecido na cidade como um local que reúne famílias, jovens, crianças nos finais de semanas, público que está à procura de algum tipo de lazer em São Borja. Também são realizados, em alguns finais de semanas, apresentações musicais, culturais e algumas manifestações sociais.

Projetos de extensão da UNIPAMPA - Campus São Borja: Responsáveis pela criação de um vínculo entre cidade e universidade. Alguns projetos são opções tanto para o público local quanto para os universitários, com a alternativa de agregar conhecimentos sobre determinado assunto ou área.

Custo de vida relativamente baixo: Por se tratar de uma cidade do interior, São Borja não apresenta um custo de vida alto. Grande parte dos estabelecimentos são próximos e não demandam gasto em táxi, por exemplo.

Cais do Porto: É um dos pontos turísticos mais contemplados pelo público da cidade, contando com um pôr do sol muito visitado nos finais de semanas.

Cinema alternativo: Na Estação Férrea é realizado o Cine Autorama, que se trata de um cinema Drive-in realizado anualmente na cidade.

Esporte: Outra alternativa é o Campeonato de Futebol Amador que reúne jovens e crianças de faixas etárias variadas para realização de um torneio no Estádio Vicente (PREFEITURA DE SÃO BORJA, 2017).

Feira do Livro: A Feira do Livro é realizada anualmente, atinge os estudantes e também promove atrações musicais e culturais nos quatro dias de feira.

Bares novos: Em 2017, abriram novos bares, como o Texas Beer e Aldeia 
Pub, que atingem o público universitário. Texas Beer é um local que comercializa cervejas artesanais, visto como diferencial. Aldeia Pub é um Bar Rock que oportuniza ao público local mostrar seus talentos e foca em unir todos os tipos de públicos (DECO ALMEIDA, 2017).

República Pub: Este estabelecimento atinge diversos públicos e gêneros musicais, possuindo como foco os universitários (DECO ALMEIDA, 2017).

D’Sabore Cafeteria, Zé Bolacha Cafeteria, Totti e Kitute: Para opções mais diárias, tomar um café ou consumir um lanche, existem essas alternativas no cenário da cidade. Eles também podem ser alternativas para se realizar trabalhos acadêmicos.

Texas Paintball: Em 2017, abriu essa alternativa de recreação em São Borja, voltada para o esporte e diretamente ligada aos jovens.

Fronteira com a Argentina: São Borja faz fronteira com o município de Santo Tomé da Argentina. A distância é de $16 \mathrm{~km}$, sendo uma alternativa para o público que vem de fora conhecer uma cultura nova e outros entretenimentos.

Após esse resumo levantado sobre o cenário de São Borja, podemos perceber que a cidade, apesar de contar com diversos aspectos rotineiros de locais pequenos, ainda assim possui alternativas que nem sempre são ressaltadas ou, até mesmo, nem chegam até o público dos estudantes da instituição.

\section{O QUE PODE A PUBLICIDADE?}

Em termos de surgimento da palavra, a publicidade possui relação direta com o verbo latino publicare, que significa "ação de tornar público" (GOMES, 2003, p. 67, grifo do autor). Porém, após a segunda metade do século XIX, iniciaram-se acontecimentos ligados ao crescimento dos mercados de grande consumo, e a publicidade se alterou como consequência da industrialização da época.

Na era da comunicação de massa, a publicidade é um instrumento de caráter econômico (GOMES, 2003), pois uma das suas funções é impulsionar, justamente, o desenvolvimento econômico. Ela pode ser interpretada como uma forma de evidenciar as características positivas de um bem, produto, serviço ou empresa; é responsável por tornar público uma ideia. Além disso, a publicidade objetiva despertar o interesse sobre determinado produto ou serviço no público consumidor. O objetivo geral da publicidade é comunicar. Através do ato da comunicação, a publicidade desperta nos indivíduos sen- 
sações, desejos e instiga ao novo.

Podemos dizer que todo indivíduo que integra a sociedade de consumo, inevitavelmente, é influenciado de alguma maneira pela persuasão da propaganda. Vivemos em sociedades de consumo; dessa forma, não conseguimos escapar dessa influência que impulsiona nossas vontades com o auxílio do inconsciente. Para atingir o seu objetivo, a comunicação publicitária utiliza a técnica de argumentação. Essa técnica se resume em dois aspectos: persuasão e informação. Informar é transmitir conhecimentos. Persuadir supõe convencer e, para tanto, é preciso motivar. Publicidade é, portanto, comunicação persuasiva, que se caracteriza por ser "persuasão deliberada, orientada a conseguir determinados efeitos, utilizando técnicas de comunicação e psicológicas, de certas formas, coercitivas" (SMITH, 1975 apud GOMES, 2003. p. 35).

Vale a pena ressaltar que um produto ou serviço não será necessariamente interpretado, recebido ou compreendido da mesma forma em todos os lugares do mundo, em todas as culturas, e, por isso, as mensagens expostas nas propagandas devem estar adaptadas à cultura que esses indivíduos estão inseridos (SILVEIRA; PERUZZOLO; AREU, 2009). Por isso, é através das características que o público-alvo apresenta que são levados em conta quais aspectos de linguagem utilizar na hora da propagação da ideia.

Esse recorte nos possibilita pontuarmos algumas ações entendidas pelos autores como possíveis de serem realizadas pela publicidade. Isto é, o que pode a publicidade? Pode evidenciar as características positivas de um bem, produto, empresa ou serviço; despertar o interesse no indivíduo sobre determinado assunto e/ou impulsionar a sua vontade; propor novas experiências, novas atitudes, novas ações; informar e persuadir; tornar conhecido um detalhe até então despercebido; propagar condutas e estilos de vida; eliminar barreiras psicológicas dos indivíduos.

\section{IMAGINÁRIO SOCIAL E PUBLICIDADE}

Agora resgatamos os pontos vistos no capítulo anterior para que possamos realizar a reflexão através dos pontos levantados. Ou seja, esses pontos guiam a nossa discussão e, com o auxílio deles, relacionamos o que vimos anteriormente a fim de mostrarmos quais as possibilidades que a publicidade apresenta para uma mudança gradativa no imaginário em questão.

\subsection{A publicidade pode evidenciar as características positivas de um}




\section{bem, produto, empresa ou serviço}

Em nossa reflexão, lidamos com o imaginário construído sobre estudar em uma universidade federal em São Borja. Tal imaginário pode ser interpretado como negativo, pois a cidade não é constituída por aspectos tradicionais de entretenimento e lazer ligados à "vida universitária".

Através desse argumento, levantamos as seguintes características de São Borja que podem ser consideradas positivas, de modo que a publicidade poderia delas aproveitar-se: UNIPAMPA - campus São Borja conta com estrutura e corpo docente qualificados; a universidade possui classificação favorável em termos de avaliação; custo de vida da cidade não é alto; há eventos culturais; há espaços para lazer ao ar livre; há estabelecimentos que podem interessar ao público universitário; cidade próxima a outro país; há um cinema alternativo.

\subsection{A publicidade pode despertar o interesse no indivíduo sobre deter-} minado assunto e/ou impulsionar a sua vontade

Existem aspectos que nem sempre são reconhecidos pelos indivíduos e acabam passando despercebidos. Um dos traços da publicidade é levar ao público aquilo que ele não conhece, ou conhece mas não se interessa, ou não reconhece como válido. No nosso caso sobre São Borja, os jovens universitários nem sempre sabem das alternativas que estão à sua volta e, no momento que essas alternativas são informadas, podem impulsionar sua vontade de tratar tal opção como algo relevante a considerar-se.

Sendo assim, ressaltamos os seguintes pontos de São Borja que, com o auxílio da publicidade, podem não passar mais despercebidos: eventos de lazer e culturais no Parcão; Campeonato de Futebol Amador; outro tipo de cinema alternativo: Sessão Pipoquinha (Projeto de extensão da UNIPAMPA - Campus São Borja).

\subsection{A publicidade pode propor novas experiências, novas atitudes,} novas ações

A propaganda lida com os nossos desejos e, através do inconsciente, comunica-nos novas alternativas. Pode impulsionar novos hábitos, saindo da nossa zona de conforto. 
O indivíduo organiza sua vida com base no imaginário construído sobre determinada situação. No nosso caso, ele possui uma ideia "fixa" sobre São Borja, que se torna negativa por não considerar aquilo que a cidade pode proporcionar de novidade, fora do habitual.

Tendo em vista esse argumento, podemos evidenciar os seguintes aspectos para a publicidade apropriar-se: Cais do Porto como alternativa de lazer; Cine Autorama; Feira do Livro; Texas Paintball; novo estilo de vida de acordo com as alternativas que São Borja apresenta.

\subsection{A publicidade pode informar e persuadir}

Para que possamos aderir à imagem de marca positiva de um dado produto ou serviço, precisamos estar conscientes dos pontos positivos que ele possui, mas não apenas isso: há necessidade de que, em algum momento, sejamos convencidos que essa adesão vale a pena, a ponto da comunicação publicitária atingir o seu objetivo final. Toda informação sobre determinado assunto pode ser convencida através da persuasão.

Desta forma, apresentamos os seguintes aspectos que podem ser informados/agregados a fim da publicidade persuadir o público universitário: bares e cafeterias em São Borja podem aderir a mais promoções para universitários; eventos culturais; alternativas de lazer ao ar livre; estrutura e corpo docente qualificado da universidade; classificação favorável em termos de avaliação da UNIPAMPA; Projetos de Extensão; museus.

\subsection{A publicidade pode propagar estilos de vida}

Os estudantes e/ou futuros estudantes possuem em mente o imaginário de, durante a graduação, levar o estilo de vida intitulado "vida universitária" com shoppings, diversas opções de entretenimento e lazer, cinema, etc. Mas em São Borja, não existem essas alternativas consagradas de entretenimento. A cidade apresenta algumas dessas opções citadas, porém em um contexto mais limitado que nem sempre satisfaz o público.

Destacamos as seguintes alternativas que podem se encaixar no estilo de vida dos universitários em São Borja: eventos culturais: Feira do Livro, Campeonato de Futebol Amador e eventos no Parcão; lazer ao ar livre; bares e cafeterias; perto da Argentina; cinemas alternativos. 


\subsection{A publicidade pode propagar estilos de vida}

A publicidade lida com o inconsciente do indivíduo, de modo que, por vezes, consegue eliminar preconceitos ou visões sobre algo. Ela faz/incentiva com que o indivíduo pense de outra maneira, que reconheça o outro lado da situação.

Sabemos que São Borja não possui muitas alternativas de entretenimento aos universitários, porém, apresenta algumas opções que podem serem vistas de outra forma no momento que a publicidade mostra os fatores positivos: vida noturna limitada; cidade histórica; Cais do Porto; Parcão; eventos culturais; Sessão Pipoquinha e Cinema Drive In; Projetos de Extensão; Feira do Livro; alternativas voltadas ao esporte.

\section{CONSIDERAÇÕES}

Estudarmos um dos possíveis fatores determinantes para a evasão e não preenchimento de vagas na UNIPAMPA - Campus São Borja não é tarefa simples, visto que se trata de um assunto pouco explorado e de fenômenos complexos, que não podem ser reduzidos a explicações ligeiras. Porém, conseguimos relacionar os nossos conceitos de imaginário social/publicidade juntamente com o cenário de São Borja/UNIPAMPA - campus São Borja, de modo que construímos argumentos de reflexão para o presente trabaIho.

Percebemos que o imaginário social envolve tradição de pensamento, algo não questionado. O imaginário nutrido não se realiza, ao menos inicialmente, no cenário encontrado ou projetado em São Borja, principalmente, pela cidade não oferecer tantas opções de lazer e entretenimento voltados ao público em questão. Com isso, consideramos que os estudantes e/ou futuros estudantes podem levar como fator impulsionador de evasão ou não preenchimento das vagas essa não sincronia entre a cidade e o imaginário. Ou seja, relevam mais esse aspecto do que o fato da UNIPAMPA - campus São Borja se tratar de uma universidade de qualidade e oferecer recursos vantajosos aos estudantes.

Sabemos que a cidade não conta com inúmeras alternativas de lazer e entretenimento aos jovens, mas, ainda assim, ela oferece algumas opções. Existem diversos eventos culturais que são realizados frequentemente no Parcão, visto como lugar para lazer ao ar livre; cinemas alternativos; bares e cafeterias, etc. Através desse argumento, entendemos que a publicidade 
pode ser vista, após o contexto apresentado, como uma maneira de melhorar o imaginário social dos estudantes e/ou futuros estudantes sobre estudar na UNIPAMPA em São Borja.

Enfatizamos que a publicidade pode ser utilizada como uma medida que possa modificar o contexto apresentado, não como um fator que gerará mudanças significativas imediatas, mas como tentativa de tornar a situação gradativamente mais positiva.

Por fim, vale enfatizarmos que este trabalho se constitui em apenas um passo, ainda assim em aberto, para que mudanças no cenário em questão sejam, de fato, sentidas socialmente. De qualquer maneira, a nossa reflexão fica disponível para que possa servir de estímulo a estudantes que se interessam por esse tema. Outra possibilidade de continuação de estudos tange ao pensar na UNIPAMPA - campus São Borja como um meio que contribui com o desenvolvimento econômico da cidade.

\section{REFERÊNCIAS}

CASTORIADIS, Cornelius. A instituição imaginária da sociedade. São Paulo: Paz e Terra, 1975.

CORRÊA, Roberto. Planejamento de Propaganda. São Paulo: Global, 2008.

DECO ALMEIDA. São Borja. 2017. Aldeia Pub. Disponível em: <http://decoalmeida.com.br/ aldeia-pub/>. Acesso em: 20 de outubro de 2017.

ESPIG, Márcia. O conceito de imaginário: reflexões acerca de sua utilização pela História. Textura. Canoas, v. 6, n. 9, p. 49-56, jun/nov. 2004.

FOLHA DE SÃO BORJA. Município de São Borja. São Borja. rs. 2017. Disponível em: <http:// www.folhadesaoborja.com.br/index.php/municipio>. Acesso em: 25 de abril de 2017.

IBGE. São Borja, Rio Grande do Sul, Brasil. Brasil. 2016. Disponível em: <https://cidades. ibge.gov.br/v4/brasil/rs/sao-borja/panorama>. Acesso em: 20 maio de 2017.

MORAES, Denis de. Imaginário social e hegemonia cultural. Acessa Mais Comunicação, Especial para Gramsci e o Brasil. Rio de Janeiro, jul. 2002. Disponível em: <http://www. acessa.com/gramsci/?page=visualizar\&id=297>. Acesso em: 03 maio de 2017 .

PERUZZOLO, Adair C. Publicitar, isto é, fazer desejar. IN: SILVEIRA, Ada C. M.; PERUZZOLO, Adair C.; AREU, Graciela I. P. Caminhos da publicidade e propaganda: marcas, identidade e discurso. Santa Maria, FACOS-UFSM, 2009.

PORTAL DO BRASIL. Ache tudo e região. Geografia de São Borja. Disponível em: <http:// achetudoeregiao.com.br/rs/sao_borja/geografia.htm>. Acesso em: 23 de setembro de 2017.

PREFEITURA DE SÃO BORJA. História de São Borja. São Borja.rs. 2010. Disponível em: $<$ http://www.saoborja.rs.gov.br/index.php?option=com_content\&view=article\&id=66\&ltemid=1329>.Acesso em: abr. 2017. 
SARMANHO, Andréia. Último cinema não é bem recebido em São Borja. Território Unipampa. 2009. Disponível em: <http://territoriounipampa.blogspot.com.br/2009/04/ultimo-cinema-nao-e-bem-recebido-em-sao.html>. Acesso em: 25 de abril de 2017.

SILVA, Juremir Machado. As Tecnologias do Imaginário. Porto Alegre: $3^{\text {a }}$ Edição, Sulina, 2012.

UNIVERSIDADE FEDERAL DO PAMPA. Projeto Institucional. 2009. Disponível em: <http:// www.unipampa.edu.br/portal/arquivos/PROJETO_INSTITUCIONAL_16_AGo_2009.pdf.> Acesso em: 22 de abril de 2017.

UNIVERSIDADE FEDERAL DO PAMPA. Campus São Borja. 2016. Disponível em: <http://novoportal.unipampa.edu.br/saoborja/cursos/graduacao >. Acesso em: 15 de agosto de 2017 . 


\section{Gabriel Sausen Feil}

Doutor em Educação pela Universidade Federal do Rio Grande do Sul (UFRGS); mestre em Educação nas Ciências pela Universidade Regional do Noroeste do Estado do Rio Grande do Sul (UNIJUí); graduado em Comunicação Social - habilitação Publicidade e Propaganda pela mesma Universidade. E-mail: gabriel.sausen.feil@gmail.com

\section{Marcia Escobar Terra}

Publicitária formada pela Universidade Federal do Pampa. Possui conhecimento e atuação em mídias sociais (planejamento, conteúdo, monitoramento, análise de resultados e relatórios). Atualmente, trabalha na Magic Web Design e faz Pós-Graduação em Comunicação Digital E E-Branding na PUC - PR.

E-mail: marciaterrax@gmail.com

\section{Júlia Rocha Paz}

Discente na Universidade Federal do Pampa, curso de Comunicação Social - Publicidade e propaganda e integrante do Grupo de Pesquisa t3xto - CNPq.

E-mail:rp_julia@hotmail.com 